\title{
SER HOMBRE 0 SER MUJER A TRAVÉS DE LA MÚSICA: UNA ENCUESTA A JÓVENES DE BARCELONA*
}

\author{
Josep Martí \\ Consejo Superior de Investigaciones Científicas - España
}

Resumo: Este artigo trata da problemática da relação entre gênero e música. Sabemos que a música como meio de comunicação contribui também para a construção social da realidade; se nos interessamos pela música como fenômeno sócio-cultural, então o aspecto de gênero constitui uma dimensão que não pode ser ignorada. Ao longo deste artigo, apresentarei alguns dados relativos a uma pesquisa tipo survey realizada com jovens barcelonenses durante o outono de 1995. Entre os diferentes objetivos da pesquisa buscava-se obter informações sobre o significado e funções da música na sociedade catalã, com algumas questões orientadas para tratar do papel que desempenha a música nas relações de gênero. Concretamente, os resultados da amostra nos aportam dados sobre o uso da música como estratégia de identidade de gênero, assim como sobre as funções que pode exercer a música como expressão e ao mesmo tempo recurso de manutenção das relações de gênero, que em nossa sociedade caracterizam-se pela sua natureza assimétrica.

Palavras-chave: Barcelona, gênero, jovens, música.

Abstract: This article is centered around the issue of gender and music. Music, as a means of communication, also contributes to the social construction of reality. If we are interested in music as a sociocultural phenomenon, the issue of gender constitutes a special dimension which cannot be ignored. Throughout this article, I give some results of an inquiry carried out on young people of Barcelona in autumn of 1995. Among the different objectives of this inquiry was to obtain information about

* Este artículo se basa en la comunicación Música y género entre los jóvenes barceloneses presentada en el II Congreso de la Sociedad Ibérica de Etnomusicología que se organizó en Valladolid, España, en 1996. 
meaning and functions of music in Catalan society. Some of the questions dealt with the role played by music in gender relations. Concretely, the results of this inquiry provide us information about the use of music as strategy of gender identity as well about functions music can play in a society which is characterized by the asymmetrical nature of gender relations; i.e. music as expression and at the same time as resource of maintenance of specific gender relations.

Keywords: Barcelona, gender, music, youth.

¿Por qué el número de compositoras es menor al de compositores o hay relativamente pocas mujeres que toquen el saxo, la batería o se dediquen al jazz? ¿Por qué se presume tan a menudo de la existencia de músicas que rezuman esencialismos nacionalistas? ¿Por qué unas músicas se codean con el whisky de importación mientras otras lo hacen preferentemente con el vino de misa, los chatos baratos o la botella de cerveza? Creo que son cuestiones que más de un melómano, sin que tenga que considerarse musicólogo, antropólogo o sociólogo se habrá hecho alguna vez. Y de hecho, son cuestiones que sin duda conciernen a la musicología, a la antropología y a la sociología. Si por una parte parece claro que para todo aquel que se interese por la música como fenómeno sociocultural, resulta pertinente plantearse estas problemáticas, no siempre se es consciente de que las tres cuestiones mencionadas, a pesar de su diversificación aparente, tienen como base común: los procesos de creación de categorías sociales a partir de las cuales entendemos nuestra realidad, y que tienen, entre otras, la importante función de regular las relaciones entre individuos.

La música, en cuanto medio de comunicación, contribuye también a la construcción social de la realidad. La música, pues, también tiene algo que ver con sexismo, etnicidad o clasismo. A través de nuestra práctica musical contribuimos al mantenimiento de las estructuras sexistas de la sociedad, contribuimos a la existencia de la etnicidad y contribuimos también a la diferenciación clasista. Esto ya lo expresó claramente hace algunos años Otto Brusatti en un trabajo sobre música y nacionalismo: la música no constituye un arte atemporal y socialmente descontextualizado sino que es una práctica artística que cumple siempre funciones muy concretas dentro de la sociedad. De acuerdo con esta idea, la música no refleja tan sólo el espíritu de una 
época, sino que también interviene dialécticamente en la configuración de este espíritu, y va mucho más allá por tanto, de aquella visión clásica musicológica que la consideraba solamente como expresión de la época (Brusatti, 1978, p. 40). Música es comunicación, y ya sabemos que la comunicación, sea a través del lenguaje o de otros sistemas simbólicos, es epistémica, es decir, es un medio a través del cual conocemos cosas, es fuente de conocimiento, y es a través también de estos "lenguajes" que construimos nuestra realidad social (Mulvaney, 1995, p. 1).

La primera idea que querría destacar es ésta: el mundo musical es epistémico y por tanto forjador de realidades sociales. Pero no es sólo el hecho de que la música, a través de sus productos, de su práctica y de las ideas que conlleve nos puedan remitir a una cierta realidad; no es tan sólo que signifique algo; también lo puede ser. Un concierto es un acto musical, pero en según qué contextos puede ser también un acto de afirmación de clase, étnica o de género; lo mismo sucede con las ideas, y lo mismo sucede con los productos musicales. Por todo ello podemos estar seguros de que no hay lenguaje o sistema simbólico que sea neutral. Tal como lo expresara Cohen, todo simbolismo está íntimamente ligado con el reparto, mantenimiento y ejercicio del poder (Cohen, 1974, p. 20 apud Delgado, 1986, p. 20), y en relación al género, tema central de este artículo: "a discusión de las relaciones entre los sexos es una forma de discutir problemas relativos al poder, a la distribución de la riqueza, a la justicia e injusticia" (Mead, 1975, p. 77). Y dado que todo discurso sobre la diversidad sexual es también un discurso sobre el poder, en nuestro mundo actual, los sexualmente diferentes se organizan para defenderse y modificar determinadas estructuras políticas (Plummer, 1991, p. 152).

Uno de los elementos esenciales de nuestra cultura es aquel que se basa en un cierto tipo de saberes de la vida cotidiana que dan por sentado la naturalidad de las diferenciaciones socialmente establecidas entre los sexos masculino y femenino. Esto presupone la inevitable adscripción de una persona en este sistema categorial: Cada uno de nosotros es visto como perteneciente a uno u otro sexo, y nadie puede escapar a esta estricta clasificación binaria (Gildemeister, 1988, p. 495-496). Ya antes de nacer, el entorno familiar del futuro niño no ahorra esfuerzos en conjeturar sobre cuál será su sexo; nuestra cultura tradicional, por ejemplo, conoce numerosos recursos para adivinarlo, y en nuestra actual sociedad, es muy normal que se tengan preparados vestidos y pañales azules si el que ha de nacer es niño, o de color rosa si es niña. La 
clasificación binaria hombre/ mujer es un marco categorial del pensamiento cotidiano; así son identificados y pensados los géneros. Dada la relevancia social de esta categorización, podemos suponer que toda transgresión al sistema originará fuertes patrones de rechazo. Sólo hace falta pensar en la infravaloración social en nuestra cultura de gais y lesbianas, claramente expresados por tradicionales designaciones como maricón, mariquita, marimacho, etc., palabras que por su contenido peyorativo se usan incluso también de manera descontextualizada como insulto.

La antropología, no obstante, nos ha aportado numerosas pruebas de que en otras culturas los sexos no se excluyen forzosamente de una manera tan radical. Ya en los años treinta, Margaret Mead observó que los roles sexuales en algunas culturas eran tres o incluso cuatro, o en ocasiones idénticos a los occidentales pero intercambiados. En muchas tribus de indios americanos era frecuente hallar un tercer sexo que podía actuar como masculino o femenino, según la conveniencia o el momento, como es el caso de los Navajo sin que, socialmente, ello supusiera ningún tipo de sanción negativa. Los mohave podían ir aún más lejos al contemplar la posibilidad de la mujer que quería ser hombre - hwame - y del hombre que quería ser mujer - alyha. Estos sexos intermedios eran respetados y no eran considerados como algo anormal. Los Arapesh no tenían nociones de roles, y los Tscahmbuli tenían roles definidos como los nuestros, pero cambiados según nuestra perspectiva: los hombres se comportaban como mujeres en cuanto a las prácticas artísticas o asuntos de belleza personal, y las mujeres como hombres, ganándose la vida y administrando la economía. ${ }^{1}$

La diferenciación entre sexo y género es la piedra fundamental en la que se ha basado la crítica feminista para denunciar la visión androcéntrica de nuestra realidad, aunque para ser exactos, el concepto de género no surgió dentro del debate feminista como quizás a primera vista podríamos creer sino que fue introducido en el año 1963 por el psicoanalista Robert Stoller. Con género designaba una propiedad individual como resultado de la construcción social (Hey, 1994, p. 7). Con ello se empezaba a dar la debida importancia al componente social y cultural para entender la masculinidad o la femineidad. De esta manera, a la visión de la biología sobre la diferenciación entre hombre

1 Ejemplos provenientes de las experiencias de Margaret Mead citados en Diego (1992, p. 49).

Horizontes Antropológicos, Porto Alegre, ano 5, n. 11, p. 29-51, out. 1999 
y mujer se añadía la visión sociocultural, el género: la construcción social de la realidad crea también sus diferencias.

Está claro que si nos interesamos por la música como fenómeno sociocultural, no podemos ignorar la dimensión del género. Angela McRobbie, ya afirmó de manera muy clara que, en la actualidad, no podemos tener la pretensión de entender procesos sociales sin tener en cuenta la problemática del género (apud Shepherd, 1991, p. 153). Hoy, la idea de género posee una clara relevancia heurística; la inclusión de esta categoría en la investigación musicológica significa contar con una dimensión totalmente nueva en la comprensión del fenómeno musical (Bowers, 1992, p. 27). Pero el interés de esta problemática va todavía más lejos. Los estudios sobre género nos muestran cómo se llega a construir una realidad a través de la historia y nos pueden ofrecer, por tanto, importantes indicios para conocer mejor otros ámbitos de significación dentro de la dinámica social además de la relación entre géneros. En un principio, nos pareció ya haber avanzado un buen trecho al dotar de valor heurístico a la típica oposición estructuralista naturaleza/cultura. Una cosa era el sexo como base ahistórica y pura biología, y otra el género, como constructo cultural. Pero dos décadas de investigación en este campo nos han mostrado incluso la fragilidad de esta dicotomía y apuntan también al carácter discursivo basado en el género de la noción de sexo (Laqueur, 1994, p. 27, 33): la explicación del sexo dentro del contexto de las relaciones entre género y poder; la comprensión del sexo como elemento contextual (Laqueur, 1994, p. 33, 42).

Por lo que respecta a la relación entre música y etnicidad, resulta claro que es en los casos de las minorías étnicas con reivindicaciones políticas de tipo nacionalista donde más fácil será obtener informaciones relevantes. Por lo que se refiere al género y la música, podemos pensar que un campo privilegiado de observación será el de la población joven, en lo que Talcott Parsons designase como "subcultura de los jóvenes". Podemos estar seguros de que no son tan sólo razones estéticas las que los mueve a escuchar a Sting, a Laura Pausini o a Bon Jovi. La búsqueda de identidad como generación diferenciada a la de sus progenitores tendrá que jugar un papel importante en la configuración de sus gustos musicales, y lo mismo cabe esperar en lo que concierne a la configuración de su identidad de género, algo que tendrá que ser especialmente marcado en esta edad.

Para tratar la temática del género me centraré en este artículo en la cuestión de los gustos musicales de los jóvenes de Barcelona. Esta ciudad catalana, 
es desde el punto de vista demográfico la segunda ciudad del estado español y, hoy día, es, sin duda alguna, una de las poblaciones más dinámicas de la Europa meridional por lo que a la música e industria cultural en general se refiere. En una ciudad como Barcelona, conviven las expresiones musicales del actual mundo globalizado con las muestras de sabor más local, tanto de la población catalana como de los inmigrantes o sus descendientes de origen español o extranjero. Hablar de la música barcelonesa de las últimas décadas significa hablar tanto de jazz o de tango como de la Nova Cançó, de rock anglosajón como de rock catalán, de flamenco andaluz como de rumba gitana... $\mathrm{y}$, recientemente, además de una world music introducida rápidamente a través de los poderosos canales de difusión mundiales, se debe hablar también de los incipientes núcleos de rai surgidos entre la población de origen magrebí. Barcelona se encuentra, en definitiva, cada vez más inmersa en la escena pluricultural que caracteriza la Europa de finales de siglo XX.

A lo largo de este artículo, daré a conocer algunos datos relativos a una encuesta realizada a jóvenes barceloneses durante el otoño de $1995 .^{2}$ Entre los diferentes objetivos de la encuesta se encontraba el de obtener información sobre significado y funciones de la música en nuestra sociedad, estando orientadas algunas de las cuestiones a tratar el papel que desempeña la música en las relaciones de género.

A través de los resultados de esta encuesta, además de otros aspectos, se pretendía obtener datos sobre:

1. El uso de la música como estrategia de identidad de género.

2. La música como expresión y a la vez recurso de mantenimiento de unas relaciones de género que en nuestra sociedad se caracterizan por su naturaleza asimétrica.

El 69,2\% de los jóvenes encuestados se declaraba un gran amante de la música, y un $28,7 \%$ se inclinaba por la afirmación de que la música le gustaba bastante. Frente a este $97,9 \%$ de respuesta positiva, tan sólo un $1,4 \%$ se

\footnotetext{
2 La encuesta se realizó a estudiantes con una edad comprendida entre 17 y 23 años. Se repartieron las encuestas a un total de 54 centros de enseñanza repartidos por todos los distritos de Barcelona, y distribuidos según las variables centro público/privado, laico/religioso, de bachillerato/de formación profesional y nocturno/diurno. El número de encuestas recogidas susceptibles de análisis para el presente trabajo fue de $1.560 ; 857$ de los encuestados era de sexo femenino y 703 de sexo masculino.
}

Horizontes Antropológicos, Porto Alegre, ano 5, n. 11, p. 29-51, out. 1999 
conformaba con un "me gusta poco" y un $0,6 \%$ daba por entendi do que la música no iba con él o con ella. ${ }^{3}$ Sin entrar ahora en detalles sobre qué significa que la música guste mucho o poco, lo importante es que entre la población joven encuestada se considera la música como un "bien”, como algo enteramente positivo, algo que, por otra parte, no requiere de ninguna encuesta para elucidarlo, aunque ésta sí nos proporciona la magia de los números que reafirma la impresión que cualquier observador puede obtener de nuestra sociedad. La música es importante entre los jóvenes: se acude a conciertos, se aprenden los textos para poder canturrearlos, no se ahorra dinero en la adquisición de discos y se graban en vídeo los grupos preferidos. Pero la música hace algo más que dar sentido a sus ratos de ocio. Las vivencias musicales de los jóvenes no tan sólo aportan elementos de identificación sino también importantes puntos de referencia.

¿Existen diferencias en los gustos musicales que estén condicionadas por el "sexo"? Según la encuesta realizada entre los jóvenes barceloneses hallamos la idea de que la distinción entre hombre y mujer implica también una cierta correspondencia en cuanto a los gustos musicales se refiere. En una de las preguntas planteadas en la encuesta, se pedía la opinión sobre la presencia de posibles diferencias entre los gustos musicales de los jóvenes según el sexo. Los resultados son los siguientes:

\begin{tabular}{|lccc|}
\hline & Hombres (\%) & Mujeres (\%) & Total (\%) \\
\hline Grandes diferencias & 26,6 & 18,9 & 22,4 \\
\hline Pequenas diferencias & 47,0 & 54,4 & 51,0 \\
\hline Inexistentes & 14,2 & 18,4 & 16,6 \\
\hline Ns/nc & 12,0 & 8,3 & 10,0 \\
\hline
\end{tabular}

Gustos musicales: diferencias según sexo.

\begin{tabular}{lcr}
\hline Por sexos: & Hombres & Mujeres \\
1. me gusta mucho & $63,3 \%$ & $74,1 \%$ \\
2. me gusta bastante & $33,9 \%$ & $24,6 \%$ \\
3. me gusta poco & $2,0 \%$ & $1,0 \%$ \\
4. no me gusta & $0,8 \%$ & $0,3 \%$
\end{tabular}


Tan sólo un $16,6 \%$ de los encuestados afirma que no existe ninguna diferencia. La percepción de la diferencia es el factor básico de todo proceso identitario. Lo es en el caso de la etnicidad, del clasismo y del género. En todos estos casos nos hallamos ante una búsqueda y establecimiento de expresiones indexicales que tienen como finalidad reforzar una diferenciación basada en el distinto lugar de nacimiento, en la diferente distribución de riqueza o en la diferenciación sexual. En nuestra sociedad, el cuerpo, los gestos, el vestido o el peinado son expresiones indexicales destinadas a marcar un orden, una adscripción de género. También el uso que se da a la música contribuye a ello. La idea de que los gustos musicales pueden ser diferentes según el sexo, no es sino un elemento expresivo más que refleja este recurso de la búsqueda de la diferencia.

Como datos de interés en las respuestas a esta pregunta concreta, además de los porcentajes obtenidos, podemos contar con dos hechos concretos:

1. La mayor parte de los encuestados afirma la existencia de una diferenciación en alto o pequeño grado entre los gustos musicales de hombres y mujeres. No obstante al preguntárseles posteriormente por algunos ejemplos determinados que reflejen esta diferencia, un notable número de las respuestas aparecen en blanco; no se sabe qué contestar. ${ }^{4}$ Estos casos concretos nos muestran que la percepción de la diferencia no se fundamenta forzosamente en los datos procedentes de la experiencia cotidiana sino en una idea preestablecida sobre la diferenciación de géneros.

2. También resulta interesante observar la diferencia que podemos establecer en las respuestas según se trate de hombre o mujer. Dada la relación jerárquica que existe entre los sexos, parecerá lógico suponer que será al masculino a quien más le interese el mantenimiento de la diferenciación. ${ }^{5}$ Y según la encuesta, efectivamente, vemos que son los

4 Porcentaje de respuestas no contestadas: para lo característico masculino: 49,64\%; para lo característico femenino: 44,69\%.

5 No obstante, también encontraremos la idea de la diferenciación, aunque valorada de manera diferente, dentro de cierto feminismo militante propio de aquellos países con una tradición feminista más marcada: "La música de las mujeres es diferente a la de los hombres, pues nosotras cantamos en base a nuestro concepto de la realidad. No seguimos el concepto masculino de realidad, las estructuras masculinas del rock, etc. Es decir, naturalmente usamos estas estructuras, pero las mujeres vemos el mundo de manera completamente diferente: nuestra manera de hablar, nuestras experiencias; nuestro mundo es totalmente diferente y así también tenemos otra cultura, otra música - es lo mismo con la literatura, la pintura y la danza de mujeres". (Kahl-Gortan, 1989, p. 7).

Horizontes Antropológicos, Porto Alegre, ano 5, n. 11, p. 29-51, out. 1999 
hombres los que más elevada puntuación ofrecen ante la opinión de que las diferencias son grandes (h: $26,6 \%$; $: 18,9 \%$ ), y la mínima ante la idea de la inexistencia de diferencias (h: 14,2\%; m: 18,4\%).

Si hallamos la opinión generalizada de que hombres y mujeres se diferencian en algún sentido en sus gustos musicales, se puede pensar que dentro de las correspondientes representaciones colectivas, exista también la idea sobre determinados estilos o géneros musicales que posean una cierta especificidad masculina o femenina. Una de las preguntas de la encuesta iba en este sentido.

Tal como ya he dicho anteriormente, el número de respuestas en blanco relativas a esta pregunta era muy superior al de los encuestados que creían que no existía ninguna diferencia. Aún así, algo más de la mitad de los encuestados aportaron datos concretos en cuanto a lo que ellos creían que podía poseer una cierta especificidad de género.

Entre las personas que expresaron una opinión concreta, hallamos una gran cantidad de diferentes respuestas, muy supeditadas como es obvio a las experiencias personales. Algunas se referían a géneros musicales como el heavy, makina o rap; otras, a posibles características de la música: romántica, lenta, bailable, etc. Y muchas respuestas se concretaban en nombres de grupos o cantantes que se caracterizaban por tener un claro predominio de fans de uno u otro sexo. No es mi intención dar ahora un listado exhaustivo de estas diferentes opciones, por otra parte muy coyunturales. No obstante, a través de su análisis me ha sido posible reunir gran parte de ellas en grupos concretos -algunos de ellos muy interrelacionados entre sí- que, por cierto, son válidos tanto para las respuestas masculinas como para las femeninas. ${ }^{6}$

6 Muchos de los encuestados aportaban en sus respuestas más de una característica específica para los sexos. Los porcentajes se dan no en función del número de encuestados sino de la totalidad de las respuestas dadas. 


\section{A. Específicamente femenino ${ }^{7}$}

\begin{tabular}{|lcc|}
\hline Géneros, estilos \& interpretes musicales & Hombres (\%) & Mujeres (\%) \\
\hline Música de carácter romántico/sentimental & $14,7 \%$ & $23,7 \%$ \\
\hline Baladas & $6,7 \%$ & $19,4 \%$ \\
\hline $\begin{array}{l}\text { Cantantes como Alejandro Sanz, Sergio Dalma y David } \\
\text { Santiesteban }\end{array}$ & $11,5 \%$ & $7,3 \%$ \\
\hline Música/canciones suaves, lenta, poco ruidosa, melódica & $8,0 \%$ & $13,9 \%$ \\
\hline $\begin{array}{l}\text { El aspecto físico del cantante (masculino) es el aspecto } \\
\text { decisivo }\end{array}$ & $11,3 \%$ & $5,5 \%$ \\
\hline $\begin{array}{l}\text { Grupos como Take That, New Kids on the Block, OBK, } \\
\text { Viceversa, Bon Jovi }\end{array}$ & $11,5 \%$ & $3,8 \%$ \\
\hline Makina & $8,6 \%$ & $4,9 \%$ \\
\hline Música de moda, comercial & $3,2 \%$ & $1,3 \%$ \\
\hline Pop & $5,8 \%$ & $5,7 \%$ \\
\hline $\begin{array}{l}\text { Música italiana/cantantes italianos (como Laura Pausini, } \\
\text { Marco Massini, Eros Ramazzotti) }\end{array}$ & $4,5 \%$ & $3,6 \%$ \\
\hline Música española/grupos españoles & $1,0 \%$ & $0,8 \%$ \\
\hline Rock & $2,7 \%$ & $0,9 \%$ \\
\hline Opiniones peyorativas & $1,0 \%$ & - \\
\hline $\begin{array}{l}\text { OTROS } \\
\text { Diversos cantantes }\end{array}$ & $2,9 \%$ & $3,4 \%$ \\
\hline Otros grupos & $2,0 \%$ & $0,3 \%$ \\
\hline Otros géneros & $2,3 \%$ & $2,3 \%$ \\
\hline Otros criterios & $1,0 \%$ & $2,3 \%$ \\
\hline
\end{tabular}

Los seis primeros grupos son los más importantes; superan para ambos o al menos uno de los dos sexos el 10\% del número total de respuestas. De la totalidad de las respuestas dadas, el $63,9 \%$ de las masculinas se ajustan a estos patrones, correspondencia que es mucho mayor para las mujeres: el 73,8\%.

\footnotetext{
7 Respuestas ns/nc: 44,6\% de los encuestados. El número de respuestas dadas es de 1.489, 685 por parte de los hombres y 804 por parte de las mujeres.

8 Además: techno, disco, trance, bakalao.
} 
Estos primeros grupos forman conjuntamente en realidad un complejo de diferentes elementos característicos que se hallan muy interrelacionados, y en parte pueden considerarse equivalentes. Los cantantes mencionados están considerados como que poseen un buen físico, cantan baladas, género que los mismos encuestados definen a menudo como de "música lenta, melódica y romántica". A menudo, estos cinco grupos formados expresan sencillamente diferentes aspectos - según lo que se quiera recalcar - de un mismo acontecimiento musical.

Además de las respuestas ya señaladas, también encontramos algunas opiniones por parte de los hombres que al caracterizar los gustos femeninos musicales reflejan posturas sexistas en términos peyorativos o claramente desmerecedores. En ocasiones, se considera propio del gusto femenino la música "superficial" y comercial y, aunque menudean realmente poco, tampoco faltan los términos claramente peyorativos: "mariconadas", "pop afeminado", "todo tipo de música que para mí no tiene contenido musical", "música poco desarrollada", "cantautores físicamente agradables pero de un nivel musical cuestionable", "canciones de amor de calidad nula o muy baja cantadas por algún chico con buen aspecto físico y poco cerebro o alguna chica con una campaña de marketing milionaria detrás", "música de moda, totalmente comercial y superficial", "cantantes de baladas cursis", etc. Este tipo de respuestas que aluden de manera tan directa a la idea de la superioridad masculina sobre la femenina constituyen no obstante número muy reducido. 


\section{A. Específicamente masculino ${ }^{9}$}

\begin{tabular}{|lcc|}
\hline Géneros, estilos \& interpretes musicales & Hombres (\%) & Mujeres (\%) \\
\hline Heavy ${ }^{10}$ & $31,9 \%$ & $36,2 \%$ \\
\hline Makina $^{11}$ & $19,2 \%$ & $18,5 \%$ \\
\hline Rock, Hard Rock o Rock duro & $17,0 \%$ & $14,5 \%$ \\
\hline Música dura o "más dura" & $1,7 \%$ & $9,4 \%$ \\
\hline Música estridente, ruidosa, rítmica, rápida, movida & $4,8 \%$ & $3,0 \%$ \\
\hline Punk, Ska u oi & $3,9 \%$ & $2,1 \%$ \\
\hline $\begin{array}{l}\text { Grupos musicales como Iron Maiden, } \\
\text { Bad Religion, Nirvana, Aerosmith, AC/DC, }\end{array}$ & $1,8 \%$ \\
\hline Gun's and Roses, Green Day & $3,7 \%$ & $1,4 \%$ \\
\hline Rap y Hip Hop & $1,7 \%$ & $0,8 \%$ \\
\hline $\begin{array}{l}\text { Grupos musicales como Héroes del Silencio, } \\
\text { Offspring, U2 }\end{array}$ & $1,9 \%$ & $0,1 \%$ \\
\hline Criterios alusivos a superioridad masculina & $2,1 \%$ & $0,7 \%$ \\
\hline Cantantes femeninas de buena presencia & $1,0 \%$ & $0,2 \%$ \\
\hline Música clásica & $0,8 \%$ & $0,1 \%$ \\
\hline $\begin{array}{l}\text { OTROS } \\
\text { Otros grupos }\end{array}$ & $2,6 \%$ & $0,8 \%$ \\
\hline Diversos cantantes & $1,9 \%$ & $2,0 \%$ \\
\hline Otros géneros & $3,5 \%$ & \\
\hline Otros criterios & & \\
\hline
\end{tabular}

Los cuatro primeros grupos, que representan las opiniones mayoritarias, forman el $70,0 \%$ de las respuestas masculinas y el $78,8 \%$ de las femeninas.

9 Respuestas ns/nc: 49,6\% de los encuestados. El número de respuestas dadas es de 1.143, 457 provenientes de los hombres y 686 de las mujeres.

${ }^{10}$ También grunge, hardcore y thrash.

11 También techno, disco, trance, dance, acid house y bakalao.

Horizontes Antropológicos, Porto Alegre, ano 5, n. 11, p. 29-51, out. 1999 
Comparando estos resultados con los anteriores, observamos que la máxima puntuación en aquello que se considera más específico de un sexo concreto, en el caso masculino no es una posible característica de la música como hemos visto para el caso femenino, sino un ámbito musical determinado más o menos definible por criterios formales: el heavy. Esta "masculinidad" adscrita al heavy, aunque tampoco libre de ciertas contradicciones (véase: Walser, 1993, p. 108-136), es algo que ya ha sido tenido en cuenta hace tiempo por la musicología:

Of all styles of music, heavy metal has been viewed as the epitome of maleness and only a tiny minority of women have played in this musical style. (Bayton, 1993, p. 185). ${ }^{12}$

El heavy es considerado un estilo "duro", característica que, directa o indirectamente, también encontramos en las opiniones expresadas en otros grupos de las respuestas. Algunos encuestados masculinos, a tenor de las respuestas dadas, reconocen abiertamente el rol que esta característica juega para la identidad de género: "música heavy o rock duro para hacerse los machos", "canciones más fuertes de tono, más masculinas". Este claro etiquetaje, con las connotaciones que comporta, es la causa de que en la encuesta, ante la pregunta "cuál es tu música preferida", algunas mujeres contesten "cualquier tipo de música menos el heavy". ${ }^{13}$ De hecho, son pocos los estilos o géneros musicales que son de forma expresa excluidos de los gustos musicales, y entre estos, como en ocasiones "la música clásica", "la música regional" o "las sevillanas", el heavy es el de más frecuente aparición, prueba evidente de su relevancia como elemento de significación en el mundo juvenil. ${ }^{14}$

No obstante, estos datos no tienen que hacernos pensar en una exclusividad masculina del heavy sino que tan sólo marcan una tendencia. Ya es sabido que el heavy, especialmente a partir de finales de los ochenta, se ha

12 Véase también el interesante análisis de Robert Walser (1993).

13 Aunque cuantitativamente este tipo de respuestas no es importante en la encuesta realizada, ya que no se preguntaba por "las músicas que no te gustan", creo que sí tiene una cierta importancia desde el punto de vista cualitativo.

${ }^{14}$ En las respuestas del tipo "cualquier tipo de música menos $x$ ”, lo que se señala no es de hecho una gran generosidad en las preferencias musicales que, evidentemente, no estaría de acuerdo con la competencia musical de los informantes, sino una gran conscienciación de la carga semántica otorgada a una música concreta que, por las razones que sean -estéticas o de fidelidad de género- provoca una reacción "militante" contra este ámbito musical por lo que a la propia sensibilidad de refiere.

Horizontes Antropológicos, Porto Alegre, ano 5, n. 11, p. 29-51, out. 1999 
ido configurando cada vez más en producto de consumo también para las mujeres. Según nuestra encuesta, el 13,8\% de las mujeres decía -de manera expresa- considerar el heavy ${ }^{15}$ como una de sus músicas preferidas, ${ }^{16}$ que si lo comparamos con el $20,8 \%$ de los encuestados masculinos, la diferencia no es tan grande.

Otra diferencia que me parece muy significativa es el hecho de que la figura del cantante, del pop-star, es mucho más importante para caracterizar los gustos femeninos que los masculinos. En el apartado referente a las caracterizaciones femeninas, veíamos que, dentro del grupo de opiniones mayoritarias, el tercer, quinto y sexto puesto hacían alusión a este aspecto: o bien se trataba de la caracterización de gustos musicales a través de nombres de cantantes y grupos concretos, o bien se mencionaba la importancia de su presencia atractiva. En el caso masculino, esta concretización muestra un porcentaje muy reducido.

Si en el caso de las caracterizaciones de los gustos femeninos encontrábamos algunas respuestas sexistas peyorativas en relación a la mujer, en este caso encontramos también por parte de las respuestas masculinas aquellas que denotan una cierta superioridad masculina, aunque en un tanto por ciento realmente pequeño $(2,1 \%)$ :

"Nuestras preferencias son más inteligentes", "buena música o de mejor calidad que la propia de las mujeres", "buena música, independientemente del aspecto de los intérpretes", "más diversidad musical", "no nos dejamos llevar por las apariencias".

También encontramos alguna respuesta sexista por parte de las mujeres en relación a la música de los hombres, pero muchas menos y prácticamente anecdódicas dado que no superan el 1\%:

"No tienen gusto por la música", "música bruta", "sólo ruido", "grosera".

En las respuestas femeninas, en alguna ocasión, se marca expresamente para los hombres la ausencia de lo que se considera típico para las mujeres, como "no les gusta la música romántica" o "música que no exprese o contenga

15 Se incluye también el grunge, hardcore y thrash.

16 En muy pocas de estas respuestas (el 0,4\% de las mujeres) se hablaba de "heavy blando". 
sentimientos", "las baladas no les van", afirmaciones que acentúan de manera especial la en ocasiones clara percepción de la polarización de los gustos musicales según el sexo. Pero esta polarización se refleja cuantitativamente mucho más en las oposiciones que buena parte de los encuestados establecía en sus respuestas: pop/heavy, música suave/música dura, baladas/rock, música con sentimiento/música sin sentimiento, romántica/no romántica, tranquila/ruidosa. En definitiva, sexo débil versus sexo fuerte. Son los mismos argumentos que dentro del lenguaje androcéntrico de la musicología no han dudado de calificar de "masculinas" a épocas como el barroco o el clasicismo y de "femenino" al romanticismo. La música potente de un Handel o un Beethoven frente al cariz intimista de Schubert o Chopin, dicotomía que en el mundo juvenil barcelonés se expresa, por una parte, mediante un género como el heavy, íntimamente ligado a la noción de "power", y por otra parte mediante cantantes como Sergio Dalma o Alejandro Sanz. El ámbito ideacional que envuelve las vivencias musicales de los jóvenes se encuentra en directa correspondencia con la típica caracterización social para los sexos: fuerza, dureza y potencia por una parte, y sentimentalismo por la otra.

Es interesante observar, que tanto para hombres como para mujeres, resulta más fácil caracterizar o estereotipar lo típicamente femenino que lo masculino dado que hay más respuestas para el primer caso. ${ }^{17} \mathrm{Si}$ partimos de la base que es siempre más fácil estereotipar al "otro", dado que todo proceso de estereotipación implica una simplificación de los datos que nos aporta la realidad, podríamos deducir quizás que ha habido una cierta asimilación por parte del género femenino de elementos ideológicos masculinos. Significativamente, es en las respuestas de las mujeres y prácticamente nunca en las de los hombres, donde en ocasiones descubrimos una cierta visión crítica hacia esta estereotipación, distanciándose personalmente de lo que ellas consideran la opinión generalizada de su entorno:

"Siempre se ha dicho que el rock duro es típico del hombre y la música romántica es de chicas. Esto es puro machismo". "Ejemplos como Sergio Dalma no creo que sean una preferencia de la mujer, sino que es un prejuicio del hombre". "Las chicas suelen preferir baladas de amor, pero no tiene porque ser así (quizás es porque somos más sentimentales), pero a mí, en particular, me gusta más la

${ }_{17} \mathrm{Si}$ en las respuestas de las mujeres, la diferencia es bastante grande -808 por $686-$, en el caso de las respuestas masculinas, es mucho más marcada: 685 contra 457. 
música con ritmo". "Supongo que la música heavy es más escuchada por los chicos que por las chicas, aunque a mí también me gusta y soy chica". "[A los chicos les gusta la música] algo más dura y un poco también que vaya en contra de la mujer, ya que así se refuerza su 'masculinidad"”. "[A los chicos les gusta] la música que los haga sentirse hombres, ésta que es más dura, ya que por sí solos no podrán llegar nunca a ser nada". "A la mayoría [de los chicos] creo que les gusta un tipo de música más heavy: hardcore, máquina, etc....pero en el fondo, aunque no lo quieran admitir, es seguro que más de una vez han tarareado alguna canción de Alejandro Sanz, etc”. "[A los chicos les gusta] el trance; es como si les hiciese ser más hombres, mejores y los que no lo escuchan es como si fuesen inferiores o algo así; es como si se discriminasen entre ellos".

Este tipo de respuestas constituyen una franca minoría, pero no por ello dejan de ser significativas y sumamente interesantes ya que reconocen la importancia de la ideología en la construcción simbólica de la realidad.

También por parte de las mujeres no faltan aquellas respuestas en las que se pone de manifiesto una cierta confrontación entre grupos de género expresada en términos musicales:

"[A las chicas nos gustan] grupos como OBK, viceversa, que los chicos creen cursis". "[A las chicas nos gusta] música romántica o baladas de amor que los chicos encuentran ridiculas".

O bien destacan la función relacionai de la práctica musical:

"[A los chicos les gusta] máquina, y si no van a ligar, pocas veces les gustan las baladas".

Todos estos ejemplos nos muestran claramente hasta qué punto la práctica musical de los jóvenes se revela como formas articuladoras de la sexualidad según los clásicos patrones válidos para nuestra sociedad. Frente a la idea de una sexualidad masculina, agresiva, basada en la noción de fuerza y potencia se le contrapone la femenina, pasiva y mucho más ligada a la esfera sentimental. La misma caracterización, por otra parte, que los lingüistas han hallado en sus estudios sobre género y lenguaje (Mulvaney, 1995, p. 5).

Con la finalidad de profundizar en el aspecto ideacional relativo a las categorías de género, me pareció adecuado preguntar en la encuesta por la opinión sobre el hecho de que en nuestro sistema sociocultural, el número de 
compositoras fuese menor al de compositores. Como estrategia, se pedía a los encuestados, en primer lugar, que indicasen el nombre de tres de sus compositoras preferidas. Fueron muchos los jóvenes que dejaron este apartado en blanco, sin contestar. ${ }^{18}$ Sintomático es también el hecho de que una gran parte de los encuestados sobreleyendo la pregunta, indicasen el nombre de compositores masculinos (que después muchos de ellos tacharon sin reemplazarlos por los correspondientes femeninos). La siguiente pregunta se centraba ya directamente en las razones por las que hay menos compositoras. Creí que una pregunta de este tipo podría aportar abundante información sobre cómo es percibida la relación de género en relación con la música. Las respuestas fueron bastante variadas, pero tras su análisis, es posible reducirlas a cuatro apartados principales: ${ }^{19}$

\begin{tabular}{|lcc|}
\hline Menos Compositoras (razones) & Hombres (\%) & Mujeres (\%) \\
\hline No sabe/no contesta & $47,9 \%$ & $44,7 \%$ \\
\hline Debido a la naturaleza humana & $26,5 \%$ & $20,1 \%$ \\
\hline Por razones claramente socioculturales & $8,8 \%$ & $28,3 \%$ \\
\hline Otras respuestas & $6,6 \%$ & $6,7 \%$ \\
\hline
\end{tabular}

Prácticamente la mitad de los encuestados masculinos responden a esta pregunta con un sencillo "no lo sé" o bien, en casi la misma proporción, con la pregunta dejada en blanco. De este gran número de "no-respuesta" se deduce la falta de reflexión sobre este hecho particular, o el poco interés en esta reflexión, quizá en muy buena parte porque se considera la débil representación femenina en el mundo de la composición musical como un "hecho objetivo y natural" que no merece discusión. Junto al "no lo sé" menudean también los comentarios en los que se refleja un cierto desconcierto ante el hecho de que hayan muchas menos compositoras que compositores, así como de los jóvenes que abiertamente decían que "nunca se habían planteado esta pregunta".

\footnotetext{
18 Debemos tener en cuenta que el término "compositor/a" tiende a asociarse con el mundo de la música clásica. Algunos jóvenes más avispados no dudaron, no obstante, en señalar nombres de compositoras propias de la música popular moderna.

19 Respuestas totales: 720 de los hombres y 885 de las mujeres.
} 
Entre los intentos de respuestas más concretas al fenómeno dadas por los hombres, el grupo mayor lo componen aquellas que tienen como denominador común el hecho basar la menor participación de la mujer en la composición musical en "causas naturales". En estos casos, se trata de "pura casualidad", o bien la razón del fenómeno radica sencillamente en la naturaleza de los hombres y de las mujeres. Son respuestas como:

"La mujer tiene menos afición/interés por la música", "Porque el sexo femenino tiene otras vías para expresar su sensibilidad y sentimientos de los que carece el hombre" o simplemente "La mujer se dedica más al canto o al baile".

La corta respuesta de uno de los encuestados "es ley de vida" resume claramente una idea muy generalizada que demuestra claramente el típico fenómeno humano de reificar, de dar carta de naturaleza, a lo que, en muy buena medida, no es sino producto de la cultura.

La mayor parte de las respuestas de este grupo, constituye un reflejo de actitudes claramente sexistas en las que, explicando el fenómeno por causas enteramente naturales, se basan en la naturaleza del hombre en términos de superioridad a la mujer. Así encontramos respuestas como "Los hombres son más inteligentes y más creativos", "Las mujeres no sirven o no entienden tanto para hacer música", "El hombre tiene más vocación" o "Los hombres tienen un don especial para componer música". Expresadas de ésta o de similar manera, nos encontramos con un porcentaje relativamente elevado de este tipo de respuestas $(15,6 \%$ del total) sin olvidar un pequeño número de ellas expresadas de forma más burda y sexista como "el lugar de las mujeres es la cocina".

Un tercer grupo de respuestas lo forman las que aducen razones claramente socioculturales. Se trata de respuestas que son un exponente de actitudes más reflexivas y críticas y, en muy buena medida, también más reivindicativas. Dentro de este grupo, encontramos un número relativamente considerable de respuestas en las que ya se habla directamente de "discriminación", "machismo" y "sexismo" (15,5\%). Otras respuestas achacan el fenómeno a la tradición, a las convenciones sociales o a la educación $(3,6 \%)$, y un tercer complejo de respuestas creen ver en razones puramente comerciales y de marketing $(3,3 \%)$ el motivo de la supremacía masculina en el campo de la composición musical. 
El cuarto grupo de respuestas, poco importante desde el punto de vista cuantitativo, estaría formada por diversas opiniones que no aportan en realidad ninguna explicación al fenómeno. En primer lugar, se trata de aquellas respuestas en las que se dice que no se está de acuerdo con la afirmación $(3,3 \%)$ presupuesta en la pregunta: Se pone en duda la aserción sobre la superioridad numérica masculina y se dice que en realidad lo que sucede es que las compositoras son menos conocidas. En este grupo he incluido también aquellas respuestas que, más que un razonamiento, son puras tautologías, constituyendo una mera constatación del fenómeno, como por ejemplo "hay menos mujeres que hacen música" $u$ otras afirmaciones como "por la misma razón que hay menos científicas" que pueden ser interpretadas de diversas maneras y que, por tanto, no pueden incluirse en ninguno de los grupos anteriores $(2,6 \%)$.

Ante la misma pregunta, las mujeres encuestadas han respondido de una manera bastante similar. Desde el punto de vista cualitativo no hay diferencias apreciables si exceptuamos las razones más burdamente sexistas que hemos hallado entre algunos -una minoría- de los encuestados masculinos y que obviamente brillan por su ausencia entre las encuestadas. Pero desde el punto de vista cuantitativo, sí hallamos diferencias significativas que aluden a una mayor concienciación -aunque relativamente todavía escasasobre la importancia de los factores socioculturales para explicar el hecho. Las respuestas "no lo sé" son menos entre las mujeres. También lo son las que entienden el fenómeno como algo "natural"; y dentro de este subgrupo aunque mucho más débilmente representado que entre los hombres, no falta tampoco la idea de una supuesta superioridad innata masculina en el ámbito musical $(4,6 \%)$. Pero observamos sobre todo un significativo aumento en diez puntos en las respuestas que aducen causas socioculturales, principalmente razones de machismo y discriminación $(28,7 \%$ de las respuestas frente al 18,8\% de los hombres). Por último, aunque muy minoritarias, no han faltado dentro de este grupo algunas respuestas femeninas con un cierto cariz panfletario:

"porque este mundo es un mundo de asquerosos machistas que sólo quieren a las mujeres para relaciones sexuales, porque en realidad tienen miedo de nosotras porque algún día gobernaremos el mundo."

Horizontes Antropológicos, Porto Alegre, ano 5, n. 11, p. 29-51, out. 1999 


\section{Conclusiones}

En este artículo me he limitado a presentar algunos resultados de una amplia encuesta sobre los jóvenes. Estos resultados nos permiten observar cómo se adecua el ámbito ideacional del mundo musical de estos jóvenes a los mecanismos básicos que, a través de las ideologías, dan pie a la jerarquización social:

A. Se marcan diferencias.

En el ámbito social estudiado, la música, como práctica cultural, contribuye claramente a fortalecer los constructos sociales tendentes a satisfacer la necesidad de la diferencia. La gran mayoría de los encuestados creen que existen diferencias de gusto musical en función de los sexos. En el grupo de encuestados de sexo masculino se aprecia una tendencia mayor que en el femenino a subrayar estas diferencias, aspecto perfectamente coherente en toda dinámica de poder entre grupos. Son precisamente los que se hallan en situación de ventaja quienes más interés tendrán en la constatación de diferencias "objetivas" que legitimen la existencia de los diferentes grupos. Al mismo tiempo que se marcan las diferencias, se crean mecanismos de control que penalicen la transgresión de las líneas marcadas entre los diversos grupos. En líneas anteriores aludíamos al hecho de que en el lenguaje coloquial español se usan, por ejemplo, los términos despectivos "marimacho" y "mariquita" para señalar, respectivamente, aquellas mujeres u hombres que no actúan de acuerdo con los patrones establecidos, aunque si bien es verdad, que tal como ya ha sido observado, la transgresión de las mujeres no es tan duramente criticada, probablemente por el hecho de su infravaloración. Para nuestro ámbito de estudio en concreto, esta constricción se pone de manifiesto en algunas de las respuestas de las informantes en las que señalaban el interés que en ocasiones se detecta entre los chicos de negar expresamente como suyos algunos de los gustos musicales tipificados como femeninos, a pesar de que en realidad también participen de ellos.

B. Se justifican las diferencias por razones naturales.

En el caso de la cuestión del porqué hay menos compositoras que compositores, es evidente el predominio de las explicaciones que tienden a justificar estas diferencias por razones de la naturaleza humana. En contra de las razones de tipo social o cultural, toda explicación basada en la naturaleza será 
siempre más justificada, y menos susceptible al cambio. Se trata de un velado sexismo que es en realidad mucho más sintomático y efectivo que el hecho de encontrar en las respuestas algunas opiniones abiertamente discriminatorias. Estas últimas podrán ser más negativas, pero son minoritarias y su mismo carácter burdo las descalifica ante la opinión social mayoritaria de la actualidad. No es así, no obstante, con los argumentos aparentemente "objetivos" en los que se reducen las explicaciones al sexo, como categoría biológica, cuando de hecho hay que buscarlas en el género en calidad de un juego dialéctico entre componentes biológicos y construcción social. Nos hallamos ante una estrategia típica de legitimación y de mantenimiento de un statu quo determinado.

C. Se valoran comparativamente estas diferencias. Esta valoración se proyecta en los portadores.

Tanto en la caracterización de los gustos musicales según los sexos como en las explicaciones sobre el mayor número de compositores que compositoras aparecen apreciaciones que señalan superioridad musical de los varones y que cuadra perfectamente con la idea de superioridad en general atribuida al sexo masculino, con la consiguiente superior valoración social.

D. La ideología del grupo dominante es asimilada por el (los) grupo(s) supeditado(s), dando carta de validez universal a lo que de hecho no es sino una determinada definición de la realidad vinculada a un interés concreto de poder.

Este aspecto es decisivo para todo mantenimiento cómodo de la jerarquía. Algunos datos obtenidos en la encuesta como la mayor facilidad de estereotipación de los rasgos característicos femeninos sobre los masculinos, la "naturalidad" de las diferencias tal como es percibida por muchas encuestadas femeninas o la aceptación de la superioridad innata masculina en el ámbito musical por parte de algunas de ellas es elocuente en este sentido. Una parte muy considerable de las respuestas relativas a los gustos musicales según los géneros se puede resumir en la oposición duro/ romántico (=débil). No hay duda que la internalización de esta oposición como marca de la diferenciación de género tiene sus consecuencias concretas en los más variados ámbitos de la vida humana. Como detalle interesante de comentar por lo que a nuestra encuesta se refiere, es que son las mujeres quienes más se aferran a esta oposición a través de sus respuestas dadas.

Mediante los datos conseguidos en la encuesta, lo que parece evidente es todavía una muy débil concienciación de las relaciones entre música 
y determinadas problemáticas sociales como es en nuestro caso concreto la cuestión de género. Este aspecto quedó muy bien expresado en los negativos comentarios hacia la encuesta de uno de los jóvenes informantes que se quejaba diciendo: “¿Por qué nos roban tiempo para hablar de un aspecto lúdico de nuestra vida cuando hay asuntos morales en nuestra sociedad más preocupantes". Evidentemente, el gran poder de la música como agente enculturador e ideologizante estriba, en muy buena parte, en no saber ver en ella más que un mero entretenimiento.

\section{Referencias}

BAYTON, M. Feminist musical practice: problems and contradictions. In: BENNETT, T. et al. (Ed.). Rock and popular music: politics, policies, institutions. London: Routledge, 1993. p. 177-192.

BOWERS, J. Feministische Forschung in der amerikanischen Musikwissenschaft. In: HOFFMANN, F.; RIEGER, E. (Ed.). Von der Spielfrau zur Perfomance-Künstlerin. Auf der Suche nach einer Musikgeschichte der Frauen. Kassel: Furore, 1992. p. 20-39.

BRUSATTI, O. Nationalismus und Ideologie in der Musik. Tutzing: Schneider, 1978.

COHEN, A. Two dimensional man: an essay on the anthropology of power and symbolism in complex society. London: Routledge \& Kegan Paul, 1974.

DELGADO, M. De la muerte de un Dios. Barcelona: Nexos, 1986.

DIEGO, E. de. El andrógino sexuado. Madrid: Visor, 1992.

GILDEMEISTER, R. Neuere Beiträge zur Entstehung des "weiblichen Sozialcharakters". Soziale Welt, v. 39, n. 4, p. 486-503, 1988.

HEY, B. Die Entwicklung des "gender"-Konzepts vor dem Hintergrund poststrukturalistischen Denkens. L'Homme: Zeitschrift für Feministische Geschichtswissenschaft, v. 5, n. 1, p. 7-27, 1994. 
KAHL-GORTAN, K. Frauen und Musik. Kofra, n. 44, p. 3-18, 1989.

LAQUEUR, T. La construcción del sexo: cuerpo y género desde los griegos hasta Freud. Madrid: Cátedra, 1994.

MEAD, M. Diferencias sexuales: ¿innatas, aprendidas o de situación? Ethnica, n. 10, p. 75-84, 1975.

MULVANEY, B. M. Gender differences in communication: an intercultural experience. 1995. Disponible en: $<$ http://cpsr.org/cpsr/gender/mulvaney.txt $>$. Acceso en: 2 dic. 1998.

PLUMMER, K. La diversidad sexual: una perspectiva sociológica. In: NIETO, J. A. (Ed.). La sexualidad en la sociedad contemporánea: lecturas antropológicas. Madrid: Fundación Universidad-Empresa, 1991. p. 151-193.

SHEPHERD, J. Music as social text. Cambridge: Polity Press, 1991.

WALSER, R. Running with the Devil: power, gender, and madness in heavy metal music. Hanover: Wesleyan University Press, 1993. 